\title{
Severe Anthelmintic Resistance in Two Free Grazing Small holder Goat Farms in Malaysia
}

\author{
Chandrawathani $\mathbf{P}^{1 *}$, Premaalatha $\mathbf{B}^{1}$, Nurulaini $\mathbf{R}^{1}$, Erwanas Al${ }^{1}$, Zaini $\mathbf{C M}^{1}$, Aizan $\mathbf{M}^{2}$, Ramlan $\mathbf{M}^{1}$ and Khadijah $\mathbf{S}^{3}$ \\ ${ }^{1}$ Veterinary Research Institute, 59, Jalan Sultan Azlan Shah, 31400 Ipoh, Perak, Malaysia \\ ${ }^{2}$ Perak State Department of Veterinary Services, 31400 Ipoh, Perak, Malaysia \\ ${ }^{3}$ Department of Biological Sciences, Faculty of Science and Technology, Universiti Malaysia Terengganu, 21030 Kuala Terengganu, Terengganu, Malaysia
}

\begin{abstract}
The use of anthelmintics in Kinta district has been ineffective in varying degrees in small ruminants due to anthelmintic resistance. In 2012, two goat farms experiencing severe mortality up to $30 \%$ in the flock were tested for anthelmintic resistance using the Faecal Egg Count Reduction Test (FECRT) with four anthelmintic from the group; Benzimidazoles, Imidazothiazoles, Macrocyclic Lactones and Salicylanilides. Fifteen animals were used in each group and treated according to the recommended dose rates based on body weights and faecal egg counts and larval cultures were conducted. Results showed that Haemonchus contortus and Trichostongylus colubriformis in these two farms were resistant to all the four anthelmintic group tested. As these two farms were actively exporting their animals to the other farm, the results in this paper indicate that nematode resistant worms are actively dispersed to the other farms in the country. This would be a factor that will hinder the actions taken to alleviate the nematode anthelmintic resistance problem in Malaysia.
\end{abstract}

Keywords: Anthelmintic resistance; Helminthiasis; Goat farms; Anthelmintic drugs

\section{Introduction}

Helminthiasis in small ruminants has been identified as the second most important cause of mortality and morbidity in small ruminants of Malaysia [1]. Consequently, anthelmintic resistance has been reported in the small ruminant farms over the years [2-4].

In one government sheep breeding farm, multiple resistance was reported towards oxfendazole (Benzimidazoles - Bz), levamisole (Imidazothiazoles - Leva), ivermectin (Macrocyclic lactones - ML), with suspected resistance towards moxidectin (ML) [5]. Total anthelminthic failure of all five commercially available anthelmintic drug classes $\mathrm{Bz}$, Leva, ML and Salicylanilides (Clos) was also reported in five small ruminant government farms in Sabah, East Malaysia [5] and in five small ruminant government farms in Peninsular Malaysia [6].

In small ruminant private farms in Malaysia, the occurrence of multiple resistance towards two or more anthelmintics from different drug groups was reported by various authors $[3,6]$. Since government and private small ruminant farms in Malaysia are actively distributing their animals to other smallholder farmers throughout the country through trading, the severity of this problem is likely to have been widely dispersed.

In 2011, one goat farm located in Ipoh Perak had recorded mortality of $33 \%$ per month with worm infection as the main cause despite injectable ivermectin given to the animals once a year. In another farm, mortality of animals was much lower, 13-40\% mortality annually even though the animals were never treated with anthelmintics. Thus a study was conducted to evaluate the current status of nematode anthelmintic resistance in these farms, as anthelmintic resistance was never evaluated on these farms and it is suspected to occur at least on one farm.

\section{Materials and Methods}

Faecal Egg Count Reduction Test (FECRT) [7] was conducted on 2 goat farms in Ipoh, Perak to evaluate the status of resistance of nematode to four types of anthelminthics; Benzimidazoles (Albendazole, Vetpharm Laboratories (S) Pte. Ltd.), Imidazothiazoles (Levamisole,
Bovet Pharmaceutical Ltd.), Macrocyclic Lactones (Ivermectin, Man./Fab: KELA N.V.) and Salicylanilides (Closantel, Janssen Pharmaceutical N.V.). In each farm, animals were divided into 5 equal groups of 8-10 animals and then the animals were treated according to the manufacturers' recommended dose rates based on individual body weight. The animals in the control group were not given any treatment.

In each farm, pre-treatment rectal faecal samples were collected from each animal. The animals in each group were treated, while the animals in the control group were identified and no treatment was given. Faecal samples were subjected to faecal egg count using the McMaster method [8] with one egg counted equivalent to 100 eggs per gram faeces Rectal faecal samples were collected again 10 to 14 days post treatment, for faecal egg count. Faecal culture (MAFF, 1986) was conducted following the faecal egg count by pooling all samples in each farm (pre-treatment) and by treatment groups in each farm (posttreatment) to identify the species of nematodes present. Identification of species was conducted using the identification keys by Manual of Veterinary Parasitological Laboratory Techniques (1971).

Analysis of data to evaluate the status of resistance was conducted based on the calculations outlined by Coles et al. [7]. Resistance to a particular anthelminthic was considered to be present if the reduction in faecal egg count was less than $95 \%$ and the $95 \%$ lower confidence limit was less than $90 \%$. If only one of two criteria was met, the status was considered as suspected resistance. If the reduction in faecal egg

*Corresponding author: Chandrawathani $\mathrm{P}$, Veterinary Research Institute, 59, Jalan Sultan Azlan Shah, 31400 Ipoh, Perak, Malaysia, E-mail: chandra1959@gmail.com

Received March 01, 2013; Accepted July 10, 2013; Published July 12, 2013

Citation: Chandrawathani P, Premaalatha B, Nurulaini R, Erwanas AI, Zaini CM, et al. (2013) Severe Anthelmintic Resistance in Two Free Grazing Small holder Goat Farms in Malaysia. J Veterinar Sci Technol 4: 137. doi:10.4172/21577579.1000137

Copyright: () 2013 Chandrawathani P, et al. This is an open-access article distributed under the terms of the Creative Commons Attribution License, which permits unrestricted use, distribution, and reproduction in any medium, provided the original author and source are credited. 
count was more than $95 \%$ and the lower confidence limit was more than $90 \%$, the status was considered as susceptible [7].

\section{Results}

\section{Managements}

Information on the management of the animals in the farms are summarized in Table 1.

Both farms are privately owned farms with animal numbers ranging between 60-90 heads per farm. In both of the farms, the goats were crossbreds Boer and Jamnapari, as the farmers kept various breeds together in their farm since they had started farming. The two farms practised semi-intensive management, where by animals grazed for 4 hours during the day and housed in raised-floor, wooden sheds during the night.

Animals in the shed were supplied with water ad libitum, salt or mineral blocks and one of farm also provided with commercial pelleted feed. Only in one farm (Farm A) the animals were dewormed once a year with ivermectin. Another farm (Farm B) the animals were never dewormed.

\section{Anthelmintic resistance}

Farm A was found to be resistant to all drugs tested - Bz, Leva, ML and Clo while Farm B was resistant to all three drugs tested- Bz, Leva and Clo. Leva is still effective in Farm B (Table 2). The egg counts for each treatment group are given in Table 3. Pre-treatment L3 identification in Farm A indicated that Haemonchus contortus is predominant species (96\%) followed by Trichostrongylus sp (3\%) and Cooperia sp (1\%). Post treatment in Farm A showed resistance of Haemonchus contortus, Trichostrongylus sp and Cooperia sp to Benzimidazoles, Levamisole, Macrocyclic Lactones (Ivermectin, Man./Fab: KELA N.V.) and Salicylanilides (Closantel, Janssen Pharmaceutical N.V.) Haemonchus contortus is predominant species (50\%) followed by Oesophagostomum sp. (38\%) and Trichostrongylus sp (12\%) in Farm B. Post treatment in
Farm B showed resistance of Haemonchus contortus, Oesophagostomum sp. and Trichostrongylus sp to Benzimidazoles, Levamisole and Salicylanilides (Table 4) (Closantel, Janssen Pharmaceutical N.V.) and Macrocyclic Lactones (Ivermectin, Man./Fab: KELA N.V.) is the effective drug for Farm B.

\section{Discussion}

Anthelmintic drugs such as benzimidazoles, levamisole and closantel are commonly used in Malaysian goat and sheep farms to control helminthiasis. However, over the past two decades there have been complaints of ineffectiveness of these drugs as farmers can buy these easily from veterinary drug distributers. Investigations by the Veterinary Research Institute have revealed a steady increase in sheep and goats being resistant to these drugs and of late even ivermectin. Anthelmintic resistance survey conducted by Dorny et al. [2] revealed $36 \%$ of goat farms to be resistant to benzimidazoles from a survey involving 92 farms locally. It was seen that the strongyles showing resistance to benzimidazoles are Haemonchus contortus and Trichostrongylus spp. Other workers, have reported up to $75 \%$ of goat farms to be resistant to benzimidazoles $[3,8]$. In this study, both farms showed critical resistance to benzimidazoles and ivermectin indirectly indicating that these 2 drugs may have been used frequently and excessively in goats. According to Coles et al. [8] Farm 2 had a susceptible worm population which could be controlled with levamisole. In a situation like this, alternative methods of worm control such as rotational grazing, or herbal remedies can be used to alleviate the helminthiasis problem. In Malaysia, commercial farms are advised to practise zero grazing or cut and carry feeding to reduce worm infestation as drug therapy with a less than effective product would considerably increase costs. There is tremendous pressure to turn towards ecofarming, reduce drug use and implementation of sustainable practises to control helminthisis in small ruminants, the biggest cause of production losses in the tropics.

After the nationwide survey reports were published [3,8,9], the

\begin{tabular}{|c|c|c|c|c|c|c|c|c|}
\hline & Number of animals & Breed of animals & Management type & Feed & Grazing area & Mortality rate & $\begin{array}{l}\text { Deworming } \\
\text { frequency }\end{array}$ & Drug used \\
\hline Farm A & 60 & Mix & Semi-intensive & $\begin{array}{c}\text { Grass when grazing and } \\
\text { pellets while penned }\end{array}$ & $\begin{array}{c}\text { Free roaming at oil palm } \\
\text { plantation, always on the } \\
\text { same area. }\end{array}$ & $33 \%$ a month & 1/year & Ivermectin \\
\hline Farm B & 90 & Mix & Semi intensive & Only when grazing & $\begin{array}{l}\text { Free roaming, always on } \\
\text { the same area }\end{array}$ & $13-40 \%$ a year & 0 & $\begin{array}{c}\text { Animals were } \\
\text { never dewormed }\end{array}$ \\
\hline
\end{tabular}

Table 1: Summary of farm management in the two farms involved in this study.

\begin{tabular}{|l|c|c|c|c|}
\hline & \multicolumn{3}{|c|}{ FECRT Percentage } \\
\cline { 2 - 4 } & Bz & Leva & ML & $-297 \%$ \\
\hline Farm A & $94 \%$ & $33 \%$ & $-25 \%$ & $97 \%$ \\
\hline
\end{tabular}

Note : FECR <50\%-critical resistance; FECR $50 \%$ to $90 \%$-severe resistance; FECR $91 \%$ to $95 \%$ - moderate resistance

Table 2 : Anthelminthic resistance status on two smallholder farms.

\begin{tabular}{|c|c|c|c|c|c|c|}
\hline & & \multicolumn{5}{|c|}{ Faecal egg count (epg) } \\
\hline & & Control & $\mathrm{Bz}$ & Leva & ML & Clo \\
\hline \multirow{2}{*}{ Farm A } & Pre-treatment & 625 & 2729 & 1775 & 2538 & 843 \\
\hline & Post-treatment & 1550 & 2267 & 43 & 1643 & 713 \\
\hline \multirow{2}{*}{ Farm B } & Pre-treatment & 1010 & 937 & 1175 & 1362 & 3787 \\
\hline & Post-treatment & 463 & 350 & 312 & 28 & 1842 \\
\hline
\end{tabular}

Table 3: Faecal egg count from treatment and control groups for each farm. 
Citation: Chandrawathani P, Premaalatha B, Nurulaini R, Erwanas Al, Zaini CM, et al. (2013) Severe Anthelmintic Resistance in Two Free Grazing Small holder Goat Farms in Malaysia. J Veterinar Sci Technol 4: 137. doi:10.4172/2157-7579.1000137

Page 3 of 3

\begin{tabular}{|c|c|c|c|c|c|c|}
\hline & & Control & $\mathrm{Bz}$ & Leva & $\mathrm{ML}$ & Clo \\
\hline Farm A & Pre-treatment & \multicolumn{5}{|c|}{ H.contortus (96\%), Trichostrongylus sp. (3\%), Cooperia sp. (1\%) } \\
\hline & Post-treatment & $\begin{array}{l}\text { H. contortus (84\%) } \\
\text { Trichostrongylus sp. (11\%) } \\
\text { Cooperia sp. }(5 \%)\end{array}$ & $\begin{array}{l}\text { H. contortus (86\%) } \\
\text { Trichostrongylus sp. (1\%) } \\
\text { Cooperia sp. }(13 \%)\end{array}$ & $\begin{array}{l}\text { H. contortus (97\%) } \\
\text { Trichostrongylus sp. (3\%) }\end{array}$ & $\begin{array}{l}\text { H. contortus (76\%) } \\
\text { Trichostrongylus sp. (19\%) } \\
\text { Cooperia sp. }(5 \%)\end{array}$ & $\begin{array}{l}\text { H. contortus ( } 86 \%) \\
\text { Trichostrongylus sp. (1\%) } \\
\text { Cooperia sp. }(13 \%)\end{array}$ \\
\hline Farm B & Pre-treatment & \multicolumn{5}{|c|}{ H.contortus (50\%), Oesophagostomum sp. (38\%), Trichostrongylus sp. (12\%) } \\
\hline & Post-treatment & $\begin{array}{l}\text { H. contortus (47\%) } \\
\text { Trichostrongylus sp. }(22 \%) \\
\text { Cooperia sp. }(2 \%) \\
\text { Oesophagostomum sp. }(29 \%)\end{array}$ & $\begin{array}{l}\text { H. contortus (50\%) } \\
\text { Trichostrongylus sp. }(49 \%) \\
\text { Cooperia sp. }(1 \%) \\
\text { Oesophagostomum sp. }(0 \%)\end{array}$ & $\begin{array}{l}\text { H. contortus (6\%) } \\
\text { Trichostrongylus sp. }(28 \%) \\
\text { Cooperia sp. (1\%) } \\
\text { Oesophagostomum sp. }(65 \%)\end{array}$ & $\begin{array}{l}\text { H. contortus (84\%) } \\
\text { Trichostrongylus sp. }(16 \%) \\
\text { Cooperia sp. }(0 \%) \\
\text { Oesophagostomum sp. }(0 \%)\end{array}$ & $\begin{array}{l}\text { H. contortus (33\%) } \\
\text { Trichostrongylus sp. }(43 \%) \\
\text { Cooperia sp. }(3 \%) \\
\text { Oesophagostomum sp. }(21 \%)\end{array}$ \\
\hline
\end{tabular}

Table 4: Species percentage of third stage larvae from treatment groups and control.

Department of Veterinary Services have been actively advising the farmers to reduce the severity of anthelmintic resistance. Farmers were advised to improve the grazing management by rotational grazing.

\section{Acknowledgements}

The authors would like to thank the Director General, Department of Veterinary Services for granting permission to publish this paper. We also would like to thank the Director and the staff from Perak State Department of Veterinary Services, as well as the farmers involved in this study.

\section{References}

1. Fatimah I, Ranjit KD, Jainudeen MR (1985) Causes of mortality of Dorset Horn Sheep in Malaysia. Kaj Vet 17: 62-67.

2. Dorny P, Claerebout E, Vercruysse J, Sani R, Jalila A (1994) Anthelmintic resistance in goats in peninsular Malaysia. Vet Parasitol 55: 327-342.

3. Chandrawathani P, Adnan M, Waller PJ (1999) Anthelmintic resistance in sheep and goat farms in Peninsular Malaysia. Vet Parasitol 82: 305-310.
4. Chandrawathani P, Adnan M, Jamnah O (1998) The efficacy of moxidectin against trichostrongylid infection in sheep. Journal of Bioscience 9: 112-113.

5. Chandrawathani P, Jamnah O, Chaeh TS, Adnan M, Rajamanickam C (1996) Evaluation of Closantel against gastrointestinal nematodes of sheep. Journal of Bioscience 7: 83-86.

6. Khadijah S, Rahman WA, Chandrawathani P, Waller PJ, Vasuge M, et al. (2006) Small Ruminants on Private Farms in Peninsular Malaysia: Nematode Resistance to Anthelmintic. Journal Veterinary Malaysia 18: 29-32.

7. Khadijah S, Rahman WA, Chandrawathani P, Waller PJ, Vasuge M, et al. (2006) Nematode Anthelmintic Resistance in Government Small Ruminant Farms in Peninsular Malaysia. Journal Veterinary Malaysia 18: 1-5.

8. Coles GC, Bauer C, Borgsteede FHM, Geerts S, Klei TR, et al. (1992) World Association for the Advancement of Veterinary Parasitology (W.A.A.V.P.) methods for the detection of anthelmintic resistance in nematodes of veterinary importance. Veterinary Parasitology 44: 35-44.

9. Anonymous (1986) Manual of veterinary parasitological laboratory techniques. (3rdedtn), Ministry of Agriculture. Fisheries and Food. London. 